\title{
Associations between vascular risk factors and subsequent Alzheimer's disease in older adults
}

\author{
Hyewon Lee ${ }^{1 \dagger}$, Kiwon Kim² ${ }^{2 \dagger}$, Yeong Chan Lee ${ }^{3}$, Soyeon Kim³ ${ }^{3}$ Hong-Hee Won ${ }^{3}$, Tae Yang Yu ${ }^{4}$ Eun-Mi Lee ${ }^{5}$,
} Jae Myeong Kang ${ }^{6}$, Matthew Lewis ${ }^{7}$, Doh Kwan $\mathrm{Kim}^{8}$ and Woojae Myung ${ }^{*^{*}}$ (D)

\begin{abstract}
Background: The clinical guidelines related to the primary prevention of Alzheimer's disease (AD) have focused on the management of vascular risk factors. However, the link between vascular risk factors and AD in older adults remains unclear. This study aimed to determine the association between vascular risk factors and subsequent $A D$ in 178,586 older adults (age $\geq 65$ years).

Methods: Participants were recruited from 2009 through 2010 and followed up for 6 years. We assessed various vascular risk factors (total cholesterol [TC], low-density lipoprotein cholesterol [LDL-C], high-density lipoprotein cholesterol [HDL-C], triglycerides [TG], fasting glucose [FG], systolic blood pressure [SBP], diastolic blood pressure $[D B P]$, pulse pressure $[P P]$, and body mass index $[B M I])$ and their association with $A D$ incidence, categorizing each vascular factor using current clinical guidelines.
\end{abstract}

Results: AD was observed in $6.0 \%$ of participants at follow-up. All lipid profiles (TC, LDL-C, HDL-C and TG) were positively associated with the risk of AD. SBP and PP were in negative associations with AD, and DBP was positively associated with AD. BMl exhibited a negative association with AD incidence. We found no significant association between FG and AD risk. The sex difference was observed to have effects on vascular risk factors.

Conclusions: In this study, we comprehensively investigated the association between eight vascular risk factors and the risk of incident AD. Our findings suggest that multiple vascular risk factors are related to the development of $A D$ in older adults. These results can help inform future guidelines for reducing $A D$ risk.

Keywords: Alzheimer's disease, Lipids, Blood pressure, Risk factor

\section{Background}

Alzheimer's disease (AD) is among the most prevalent neurological disorders, accounting for $10.2 \%$ of the global disability-adjusted life year (DALY) [1]. Moreover, researchers have projected that over 60 million individuals

\footnotetext{
* Correspondence: wmyung@snu.ac.kr

†Hyewon Lee and Kiwon Kim contributed equally to this work as co-first authors.

${ }^{9}$ Department of Neuropsychiatry, Seoul National University Bundang Hospital, Seongnam-si, South Korea

Full list of author information is available at the end of the article
}

worldwide will be diagnosed with AD by the year 2050 [2]. Trials for AD-modifying drugs have yielded disappointing results, increasing the need for primary prevention efforts.

Current guidelines related to the primary prevention of $\mathrm{AD}$ focus on the modification of vascular risk factors (e.g., dyslipidemia, blood pressure [BP], fasting glucose [FG], or weight) [3-7]. Vascular risk factors in midlife and late-life, associated with the risk of $\mathrm{AD}$, showed inconsistent profiles, with midlife vascular risk factors increasing the AD risk, contrary to late-life factors [8]. 
Midlife hypertension has been reported to increase $\mathrm{AD}$ dementia risk [9], while late-life hypertension has an inconsistent association with $\mathrm{AD}$ dementia risk in the same research. The FG level in midlife was also reported to have an increased association with $\mathrm{AD}$ risk which was in line with late-life poor glucose control [10], but this association was not consistent with previous studies [11]. The association between lipid profile in midlife and late-life with $\mathrm{AD}$ risk is similar to that of BP. Increased lipid level in midlife was reported to increase AD risk [12], but other researchers reported mixed results with interventions $[13,14]$. However, late-life lipid level and AD risk were more complicated, demonstrating either opposite results or no significance [15]. Midlife obesity is an established risk factor for $\mathrm{AD}$, whereas late-life obesity has been proposed as a protective state, exhibiting reverse causation [16]. As it could be supported by these complex reports in midlife and late-life vascular risk factor studies, the preventive effect of modifying vascular risk factors in older adults is still insufficient.

Additionally, the majority of previous studies have examined a limited number of risk factors at a time, and some of these studies have not considered the confounding effects of comorbid illnesses or related modifiable lifestyle factors [17]. The difference on the risk of $\mathrm{AD}$ linked to vascular risk factors based on sex is also an emerging issue to be explored. This difference has been related to different factors between male and female including systematic inflammation, metabolic condition, vascular dysfunctions and immobilization [18]. In this nationwide populationbased study of older adults, we aimed to investigate the association between multiple vascular risk factors and subsequent $\mathrm{AD}$ after comprehensive adjustment for covariates. We hypothesized that the vascular risk factors in older adults could have an association with the risk of $\mathrm{AD}$, concordant with recent guidelines suggested in midlife vascular risk factors and $\mathrm{AD}$.

\section{Methods}

\section{Data source}

Data for this nationwide population-based study of older adults in South Korea were obtained from the National Health Insurance Service-Senior Cohort (NHIS-SC) database. The study was approved by the Institutional Review Board of Seoul National University Bundang Hospital, which waived the requirement for informed consent due to the nature of the study. All data were anonymized to maintain confidentiality.

The NHIS is the universal insurance provider for all of South Korea, launched in 2000 as a single-payer system combining more than 366 medical insurance payers [19]. NHIS collects medical records for all citizens, including data related to healthcare utilization (outpatient visits or admission), prescription medications, national health examination results, and demographics, to construct the National Health Insurance Database (NHID). Among the five national cohorts established by the NHIS, the NHIS-SC includes data from 558,147 older adults taken from the total eligible population (age $\geq 60$ years; 5.5 million people in 2002) using a simple random sampling method. The NHIS-SC participants were followed up from January 1, 2002, until December 31, 2015.

\section{Study design and population}

We did a nationwide retrospective cohort study using the NHIS-SC data. The assessments of several vascular risk factors (total cholesterol [TC], low-density lipoprotein cholesterol [LDL-C], high-density lipoprotein cholesterol [HDL-C], and triglycerides [TG]) were initiated in 2009. Therefore, we selected a total of 206,046 participants who had undergone a national health examination at least once between 2009 and 2010 from the 558,147 NHIS-SC participants. Then, participants who had died before $2010(n=710)$, diagnosed with any type of dementia $(n=16,969)$, with incomplete information regarding risk factors and covariates, and outlier values (exceeding the mean \pm 4 standard deviations) for any risk factors or covariates $(n=9781)$ were excluded. The final study population included 178,586 participants (Fig. 1).

\section{Construction of key variables}

Vascular risk factors collected included TC (mg/dL), LDLC $(\mathrm{mg} / \mathrm{dL})$, HDL-C $(\mathrm{mg} / \mathrm{dL})$, TG $(\mathrm{mg} / \mathrm{dL})$, FG $(\mathrm{mg} / \mathrm{dL})$, systolic BP (SBP, mmHg), diastolic BP (DBP, $\mathrm{mmHg}$ ), and body mass index (BMI, units). We assessed levels of these variables measured during the national health examination in 2009 or 2010. When health examinations were performed in both 2009 and 2010, the levels from 2010 were used. For the main analyses, continuous variables were categorized according to the current Korean guidelines for vascular risk factors [20] and the categorized variables were analyzed as the main variables. The reference levels were $<200 \mathrm{mg} / \mathrm{dL}$ for $\mathrm{TC},<100 \mathrm{mg} / \mathrm{dL}$ for $\mathrm{LDL}-\mathrm{C}, \geq 60$ $\mathrm{mg} / \mathrm{dL}$ for HDL-C, $<150 \mathrm{mg} / \mathrm{dL}$ for TG, $<70 \mathrm{mg} / \mathrm{dL}$ for FG, $<120 \mathrm{mmHg}$ for SBP, $<80 \mathrm{mmHg}$ for DBP, and $<18.5$ for BMI. Cutoff values for each category of the vascular risk factors are presented in Additional file 1: Table S1. We also constructed the pulse pressure $(\mathrm{PP})$ variable by subtracting DBP from SBP. PP is considered a surrogate marker for arterial stiffness [21] and known to be an independent predictor for cardiovascular diseases. The PP variable was categorized by its quartile cutoff due to the absence of the referent level for PP, and the first quartile (Q1) was used as a referent level. The quartile cutoffs were 


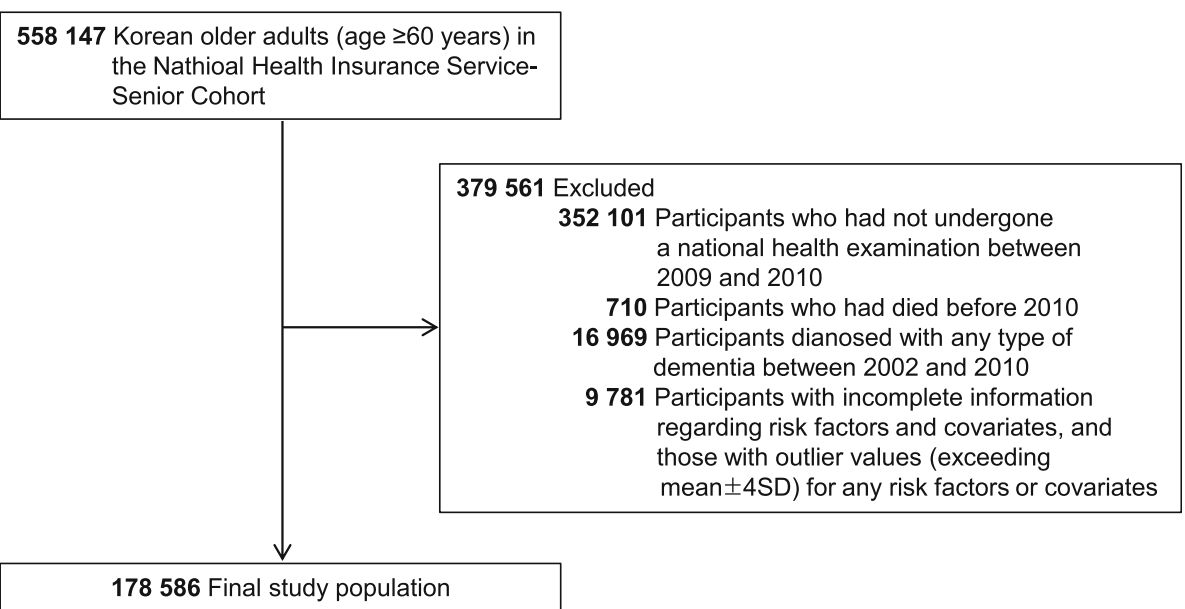

Fig. 1 Flow diagram of the study population

$42 \mathrm{mmHg}$ for $\mathrm{Q} 1-\mathrm{Q} 2,50 \mathrm{mmHg}$ for $\mathrm{Q} 2-\mathrm{Q} 3$, and 60 $\mathrm{mmHg}$ for Q3-Q4.

Incident $\mathrm{AD}$ was regarded as the primary outcome. For this study, AD incidence was defined as the first healthcare utilization according to the International Classification of Diseases, Tenth Revision (ICD-10) codes F00 or G30 (primary or secondary diagnosis), accompanied by a documented history of using cognitionenhancing medications (donepezil, rivastigmine, galantamine, or memantine) [22].

\section{Statistical analysis}

We conducted a survival analysis using the Cox proportional hazards regression model, to estimate hazard ratios (HRs) for vascular risk factors associated with subsequent AD incidence. Survival time was calculated from January 1,2010 , to the date of AD incidence, death, or the end of follow-up (December 31, 2015), whichever occurred first. Each vascular risk factor (categorical, see Additional file 1: Table S1) was first evaluated in the age- and sex-adjusted Cox model. Age was included as a continuous variable. The subsequent fully adjusted Cox model included household income (categorical, medical aid, low [1st-3rd decile], middle [4th-7th decile], or high [8th-10th decile]), smoking status (categorical, never, ex-smoker, or current smoker), alcohol consumption (categorical, rarely $[0-2$ days/week], light [3-4 days/week], or heavy [5-7 days/ week]), exercise (categorical, yes or no [1-7 days/week]), hemoglobin (continuous, g/dL), frequency of healthcare utilization (categorical, first, second, third, or fourth quartiles), depression (categorical, yes or no), Charlson Comorbidity Index (continuous), medication history (categorical [yes or no] for each medication category [dyslipidemia medication, antidiabetic medication, antihypertensive medication, antidepressants, benzodiazepines or sleeping aids, and antiplatelet medication]), and all other vascular risk factors (continuous). Household income was estimated based on insurance premiums using NHIS data. The frequency of healthcare utilization, comorbidities, and medication history was calculated based on the data from 2002 to 2010. In the analysis of TC as a major risk factor, LDL-C was excluded in the full model, and in the analysis for PP, DBP was excluded. In analyses for all other vascular risk factors, TC was excluded due to the high correlation between TC and LDL-C. Multicollinearity between all covariates was tested using a variance inflation factor (VIF), which revealed no significant collinearity (VIF $<2$ for all variables). $P$ values for linear trends were also calculated by treating median values of each categorical group as continuous variables (e.g., $173 \mathrm{mg} / \mathrm{dL}, 217 \mathrm{mg} / \mathrm{dL}$, and $257 \mathrm{mg} / \mathrm{dL}$ for each group of TC). The proportional hazard $(\mathrm{PH})$ assumption was satisfied both graphically and statistically using Schoenfeld residuals. No variables violated the PH assumption.

We examined prescription records for dyslipidemia medication, antidiabetic medication, and antihypertensive medication during the first 3 years of follow-up for all participants, who were then stratified into two groups according to each prescription history. Stratified analyses were performed to investigate whether medication intake during the follow-up period modified the association between vascular risk factors and $\mathrm{AD}$ incidence. Analyses were also stratified by sex to assess the potential effect of sex. Significant differences between the two groups were examined using an interaction term between vascular risk factor variables and group indicator variables in the total dataset.

Two-sided analyses were conducted at a significance level of .05 , and $95 \%$ CIs are reported. SAS Enterprise Guide version 7.2 (SAS Institute Inc) and R Studio version 1.0.136 (RStudio Inc: packages survival version 2.43-3 and survminer version 0.4.3) were used to perform the analyses. 


\section{Results}

\section{Characteristics of the study population}

During the 6-year follow-up period, 10,732 (6.0\%) participants had incident AD. Among them, $94.8 \%$ of the patients were prescribed with donepezil, rivastigmine, and galantamine for mild or moderate severity, while the rest of patients (5.2\%) were prescribed high doses of donepezil and memantine, which are approved for moderate or severe dementia. Table 1 presents the descriptive characteristics of the study participants in the incident $\mathrm{AD}$ and non-AD groups. Female sex, older age, medical assistance, smoking, alcohol consumption, frequent exercise, frequent healthcare utilization, comorbidities (including depression), and a history of medication use were more common in the $\mathrm{AD}$ group. Besides, the $\mathrm{AD}$ group exhibited higher TC, LDL-C, TG, and FG levels than the non$\mathrm{AD}$ group. Hemoglobin levels and BMI were lower in the $\mathrm{AD}$ group than in the non-AD group.

\section{Vascular risk factors and the risk of subsequent $A D$}

The cumulative incidence of $\mathrm{AD}$ events according to the categorized vascular risk factors based on the current Korean guidelines is presented in Fig. 2. Compared to the referent levels, higher levels of TC, LDL-C, and TG were associated with a higher cumulative incidence of $\mathrm{AD}$, whereas higher levels of BMI showed a lower cumulative $\mathrm{AD}$ incidence. Clear linear trends were not observed in other vascular risk factors.

In the age- and sex-adjusted models, highest levels of TC $(\geq 240 \mathrm{mg} / \mathrm{dL})$ and TG $(200-499 \mathrm{mg} / \mathrm{dL})$ showed a significantly higher risk of AD (TC: $\mathrm{HR}=1.085[95 \% \mathrm{CI}=$ 1.025-1.149], TG: $\mathrm{HR}=1.101 \quad$ [95\% $\mathrm{CI}=1.044-1.161]$ ) compared to the referent levels (TC, $<200 \mathrm{mg} / \mathrm{dL}$; TG, $<$ $150 \mathrm{mg} / \mathrm{dL})$, whereas highest SBP levels $(\geq 140 \mathrm{mmHg}$ vs. $<120 \mathrm{mmHg}$ ) showed a significantly lower AD risk (HR = $0.887[95 \% \mathrm{CI}=0.840-0.946])$. Other vascular risk factors exhibited no significant associations with the risk of $\mathrm{AD}$ (Table 2 and Additional file 1: Table S2).

The fully aHRs for AD incidence by vascular risk factors categorized according to the current Korean guidelines are presented in Fig. 3, Table 2, and Additional file 1: Table S2.

The associations of highest levels of TC, TG, and SBP with the incident $\mathrm{AD}$ remained significant in the full model (TC: $\mathrm{HR}=1.089$ [95\% CI $=1.025-1.156]$, TG: $\mathrm{HR}=$ $1.094[95 \% \mathrm{CI}=1.034-1.156], \mathrm{SBP}: \mathrm{HR}=0.827[95 \% \mathrm{CI}=$ $0.771-0.888])$. The risk of incident $\mathrm{AD}$ increased according to LDL-C levels until they reached $190 \mathrm{mg} / \mathrm{dL}$ (HR = $1.116[95 \% \mathrm{CI}=1.039-1.199]$ vs. $<100 \mathrm{mg} / \mathrm{dL}$ ), at which point the risk decreased $(\mathrm{HR}=1.085[95 \% \mathrm{CI}=0.966-$ 1.218]). In contrast, the risk of incident $A D$ increased according to LDL-C levels until they reached $190 \mathrm{mg} / \mathrm{dL}$ $(\mathrm{HR}=1.116[95 \% \mathrm{CI}=1.039-1.199]$ vs. $<100 \mathrm{mg} / \mathrm{dL})$, at which point the risk decreased $(\mathrm{HR}=1.085[95 \% \mathrm{CI}=$ $0.966-1.218]$ ). In contrast, HDL-C levels of $40-59 \mathrm{mg} / \mathrm{dL}$ were associated with a significantly lower risk of $\mathrm{AD}$ events $(\mathrm{HR}=0.945[95 \% \mathrm{CI}=0.904-0.988])$ than the reference level $(\geq 60 \mathrm{mg} / \mathrm{dL})$, while levels $<40 \mathrm{mg} / \mathrm{dL}$ did not significantly reduce the risk ( $\mathrm{HR}=0.941[95 \% \mathrm{CI}=0.882$ $1.004])$. The highest DBP levels $(\geq 90 \mathrm{mmHg})$ were associated with an increased risk of incident $\mathrm{AD}(\mathrm{HR}=1.110$ $[95 \% \mathrm{CI}=1.037-1.188])$ compared to the referent level $(<$ $80 \mathrm{mmHg}$ ). Finally, AD risk decreased according to BMI until reaching $35.0 \mathrm{~kg} / \mathrm{m}^{2}(\mathrm{HR}=0.901 \quad[95 \% \mathrm{CI}=0.780-$ $1.040]$ ), following which non-significant increases in risk were observed $(\mathrm{HR}=1.292[95 \% \mathrm{CI}=0.710-2.349]$ ). All vascular risk factors except FG and BMI showed a significant linear trend ( $P$ for trend $=0.019$ to $<0.0001$ ). The substantial differences in the results of the age- and sexadjusted model and the fully adjusted model could be attributed to the comprehensive adjustment of various confounders (Additional file 1: Table S3).

Figure 4 shows the cumulative incidence of $\mathrm{AD}$ events according to the quartile group (Q1-Q4) of PP. Q2-Q4 levels of PP were associated with a lower risk of AD than the Q1 level. In the age- and sex-adjusted model, the Q4 level of PP was significantly associated with a lower risk of $\mathrm{AD}$ events (HR for Q4 vs. Q1 $=0.858$ [95\% CI $=0.815-$ 0.903]). This association remained significant in the fully adjusted model ( $\mathrm{HR}$ for Q4 vs. Q1 $=0.840[95 \% \mathrm{CI}=$ $0.780-0.905])$ and exhibited a decreasing linear trend $(P$ for trend <0.0001) (Fig. 4 and Additional file 1: Table S4).

\section{Subgroup analyses according to sex and medication history}

The sex-specific associations between incident $\mathrm{AD}$ and vascular risk factors are shown in Table 2 and Additional file 1: Table S5, Table S6. The positive association between $\mathrm{AD}$ and the highest TC levels $(\geq 240 \mathrm{mg} / \mathrm{dL}$ vs. $<200 \mathrm{mg} / \mathrm{dL})$ was significant in women $(\mathrm{HR}=1.102$ [95\% CI $=1.028-1.181]$ ), but not significant in men $(\mathrm{HR}=1.055[95 \% \mathrm{CI}=0.929-1.198])$. In women, higher levels of LDL-C than the referent level $(<100 \mathrm{mg} / \mathrm{dL})$ were associated with a significantly increased risk of $\mathrm{AD}$ until they reached $190 \mathrm{mg} / \mathrm{dL} \quad(\mathrm{HR}=1.150[95 \% \mathrm{CI}=$ 1.056-1.252]), at which point the risk decreased ( $\mathrm{HR}=$ 1.095 [95\% CI $=0.961-1.247]$ ), and lower levels of HDL$C$ than the referent level $(\geq 60 \mathrm{mg} / \mathrm{dL})$ were associated with a significantly lower risk of $\mathrm{AD}(40-59 \mathrm{mg} / \mathrm{dL}$ : $\mathrm{HR}=0.943[95 \% \mathrm{CI}=0.894-0.995], \quad<40 \mathrm{mg} / \mathrm{dL}: \mathrm{HR}=$ 0.913 [95\% $\mathrm{CI}=0.840-0.991]$, trend $P=0.01$ ). In contrast, these associations with LDL-C and HDL-C were not significant in men. The positive association of $\mathrm{AD}$ with higher TG levels than the referent level $(<150 \mathrm{mg} /$ $\mathrm{dL}$ ) was observed in both sex groups. In men, TG levels of $150-199 \mathrm{mg} / \mathrm{dL}(\mathrm{HR}=1.100$ [95\% CI $=1.103-1.205])$ were significant, but levels $\geq 200 \mathrm{mg} / \mathrm{dL} \quad(\mathrm{HR}=1.084$ $[95 \% \mathrm{CI}=0.978-1.201])$ were not significant. In women, only levels $\geq 200 \mathrm{mg} / \mathrm{dL}$ exhibited a significant association $(\mathrm{HR}=1.100[95 \% \mathrm{CI}=1.030-1.176])$. Higher DBP 
Table 1 Descriptive characteristics of the study population

\begin{tabular}{|c|c|c|c|c|}
\hline & \multicolumn{3}{|c|}{ No. (\%) of participants, vascular risk factors } & \multirow[b]{2}{*}{$P$ value } \\
\hline & Total $(n=178,586)$ & $\mathrm{AD}(n=10,732)$ & Non-AD $(n=167,854)$ & \\
\hline $\operatorname{Sex}^{*}$ & & & & $<0.0001$ \\
\hline Male & $81,242(45.5)$ & $3742(34.9)$ & $77,500(46.2)$ & \\
\hline Female & $97,344(54.5)$ & $6990(65.1)$ & $90,354(53.8)$ & \\
\hline Age group* & & & & $<0.0001$ \\
\hline 65 to 69 years & $23,471(13.1)$ & $74(0.7)$ & $23,397(13.9)$ & \\
\hline 70 to 74 years & $80,333(45.0)$ & $2352(21.9)$ & $77,981(46.5)$ & \\
\hline 75 to 79 years & $48,208(27.0)$ & $3898(36.3)$ & $44,310(26.4)$ & \\
\hline Older than 80 years & $26,574(14.9)$ & $4408(41.1)$ & $22,166(13.2)$ & \\
\hline Income, deciles* & & & & $<0.0001$ \\
\hline Medical aid & $1899(1.1)$ & $258(2.4)$ & $1641(1.0)$ & \\
\hline Low (1st-3rd decile) & $36,433(20.4)$ & $2037(19.0)$ & $34,396(20.5)$ & \\
\hline Middle (4th-7th decile) & $48,421(27.1)$ & $2832(26.4)$ & $45,589(27.2)$ & \\
\hline High (8th-10th decile) & $91,833(51.4)$ & $5605(52.2)$ & $86,228(51.4)$ & \\
\hline \multicolumn{5}{|l|}{ Lifestyles } \\
\hline Smoking status* & & & & $<0.0001$ \\
\hline Never smoking & $130,940(73.3)$ & $8475(79.0)$ & $122,465(73.0)$ & \\
\hline Ex-smoking & $26,613(14.9)$ & $1230(11.5)$ & $25,383(15.1)$ & \\
\hline Current smoking & $21,033(11.8)$ & $1027(9.6)$ & 20,006 (11.9) & \\
\hline Alcohol consumption* & & & & $<0.0001$ \\
\hline Rarely ( $0-2$ days/week) & $158,170(88.6)$ & 9795 (91.3) & $148,375(88.4)$ & \\
\hline Light (3-4 days/week) & $9275(5.2)$ & $376(3.5)$ & $8899(5.3)$ & \\
\hline Heavy (5-7 days/week) & $11,141(6.2)$ & $561(5.2)$ & $10,580(6.3)$ & \\
\hline Exercise $^{*}$ & & & & $<0.0001$ \\
\hline No exercise & $121,405(68.0)$ & 7795 (72.6) & $113,610(67.7)$ & \\
\hline Exercise & $57,181(32.0)$ & $2937(27.4)$ & $54,244(32.3)$ & \\
\hline \multicolumn{5}{|l|}{ Comorbidities } \\
\hline Depression* & $14,075(7.9)$ & $1270(11.8)$ & $12,805(7.6)$ & $<0.0001$ \\
\hline Charlson Comorbidity Index* & & & & $<0.0001$ \\
\hline 0 & $21,574(12.1)$ & $975(9.1)$ & $20,599(12.3)$ & \\
\hline 1 & $40,912(22.9)$ & $2014(18.8)$ & $38,898(23.2)$ & \\
\hline$\geq 2$ & $116,100(65.0)$ & $7743(72.2)$ & $108,357(64.6)$ & \\
\hline Healthcare visit frequency ${ }^{*, \dagger}$ & & & & $<0.0001$ \\
\hline First quartile & $44,748(25.1)$ & $1904(17.7)$ & $42,844(25.5)$ & \\
\hline Second quartile & $44,669(25.0)$ & $2325(21.7)$ & $42,344(25.2)$ & \\
\hline Third quartile & $44,595(25.0)$ & $2751(25.6)$ & $41,844(24.9)$ & \\
\hline Fourth quartile & $44,574(25.0)$ & $3752(35.0)$ & $40,822(24.3)$ & \\
\hline \multicolumn{5}{|l|}{ Medication history* } \\
\hline HMG-CoA reductase inhibitors & $41,904(23.5)$ & $2611(24.3)$ & $39,293(23.4)$ & 0.029 \\
\hline Antidiabetic medication & $28,439(15.9)$ & 2056 (19.2) & $26,383(15.7)$ & $<0.0001$ \\
\hline Antihypertensive medication & $106,098(59.4)$ & $6101(62.4)$ & $99,397(59.2)$ & $<0.0001$ \\
\hline Antidepressants & $10,318(5.8)$ & $1028(9.6)$ & $9290(5.5)$ & $<0.0001$ \\
\hline Benzodiazepine and sleep pill & $47,203(26.4)$ & $3835(35.7)$ & $43,368(25.8)$ & $<0.0001$ \\
\hline Antiplatelet medication & $50,994(28.6)$ & $3491(32.5)$ & 47,503 (28.3) & $<0.0001$ \\
\hline
\end{tabular}


Table 1 Descriptive characteristics of the study population (Continued)

\begin{tabular}{|c|c|c|c|c|}
\hline & \multicolumn{3}{|c|}{ No. (\%) of participants, vascular risk factors } & \multirow[b]{2}{*}{$P$ value } \\
\hline & Total $(n=178,586)$ & $A D(n=10,732)$ & Non-AD $(n=167,854)$ & \\
\hline \multicolumn{5}{|l|}{ Laboratory findings, mean (SD) } \\
\hline \multicolumn{5}{|l|}{ Cholesterol level, mg/dL ${ }^{\ddagger}$} \\
\hline Total cholesterol & $196.4(38.4)$ & $198.6(39.3)$ & $196.3(38.4)$ & $<0.0001$ \\
\hline LDL-C & $116.2(35.3)$ & $117.6(35.8)$ & $116.1(35.2)$ & $<0.0001$ \\
\hline $\mathrm{HDL}-\mathrm{C}$ & $52.8(13.4)$ & $52.9(13.7)$ & $52.8(13.4)$ & 0.211 \\
\hline Triglyceride & $135.6(68.6)$ & $138.6(69.9)$ & $135.4(68.5)$ & $<0.0001$ \\
\hline Fasting glucose, $\mathrm{mg} / \mathrm{dL}^{\neq}$ & $101.9(21.0)$ & $102.8(22.3)$ & $101.9(20.9)$ & $<0.0001$ \\
\hline Hemoglobin, $\mathrm{g} / \mathrm{dL}^{\ddagger}$ & $13.3(1.5)$ & $13.0(1.4)$ & $13.3(1.5)$ & $<0.0001$ \\
\hline \multicolumn{5}{|c|}{ Physical examination findings, mean $(S D)^{\ddagger}$} \\
\hline Systolic blood pressure, $\mathrm{mmHg}$ & $130.3(15.9)$ & $130.4(16.4)$ & $130.3(15.9)$ & 0.534 \\
\hline Diastolic blood pressure, $\mathrm{mmHg}$ & $78.0(9.8)$ & $78.1(10.1)$ & $78.1(9.8)$ & 0.728 \\
\hline Body mass index, $\mathrm{kg} / \mathrm{m}^{2}$ & $23.8(3.1)$ & $23.5(3.2)$ & $23.8(3.1)$ & $<0.0001$ \\
\hline
\end{tabular}

*Group comparisons by chi-squared tests

${ }^{\dagger}$ The fourth quartile group had the highest frequency of medical visits

${ }^{\ddagger}$ Group comparisons by $T$ tests

( $\geq 90 \mathrm{mmHg}$ ) was associated with an increased risk of incident $\mathrm{AD}(\mathrm{HR}=1.158$ [95\% $\mathrm{CI}=1.066-1.259])$. However, increasing SBP (up to $\geq 140 \mathrm{mmHg}$ ) was linearly associated with decreases in the risk of incident $\mathrm{AD}$ $(\mathrm{HR}=0.800$, [95\% CI $=0.734-0.873])$ in women, but not significant in men. Higher BMI levels than the referent level $\left(18.5 \mathrm{~kg} / \mathrm{m}^{2}\right)$ showed a significant negative association with $\mathrm{AD}$ risk until reaching $35.0 \mathrm{~kg} / \mathrm{m}^{2}$ (HR = $0.828[95 \% \mathrm{CI}=0.702-0.978])$ in women, whereas it showed a positive non-significant association in men ( $\geq$ $35.0 \mathrm{~kg} / \mathrm{m}^{2}: \mathrm{HR}=2.428$ [95\% CI $\left.=0.062-9.792\right]$ ). Compared to Q1 levels, Q4 levels of PP were associated with a lower risk of $\mathrm{AD}$ in both sex groups, but it was not significant in men (Fig. 4 and Additional file 1: Table S4). However, these differences were not significant for all vascular risk factors ( $P$ for interaction $=0.09-0.77$ ).

Furthermore, there was no evidence of an interaction between vascular risk factors and medication during the first 3 years of follow-up regarding incident AD (all $P$ for interaction $>0.10$, Additional file 1: Table S7).

\section{Discussion}

In this nationwide population-based study of 178,586 Korean older adults, we investigated the association between eight vascular risk factors and the risk of incident AD. As summarized in Fig. 3, lipid profiles including TC, LDL-C, HDL-C, and TG exhibited positive associations with $\mathrm{AD}$ risk. SBP and BMI exhibited a negative association with $\mathrm{AD}$ incidence, except for the highest group. The risk of $\mathrm{AD}$ exhibited a significantly positive association with DBP. Subgroup analyses revealed a significant positive association between TC, LDL-C, HDL$\mathrm{C}, \mathrm{TG}, \mathrm{DBP}$, and $\mathrm{AD}$ risk in women. Otherwise, a significantly negative association between $\mathrm{AD}$ risk and SBP was observed in women. A significant positive association between AD risk and TG was observed in men.

The largest recent meta-analysis, which included 23,338 participants, reported no association between levels of lipid profiles (including TC, LDL-C, and TG) in late-life and $\mathrm{AD}$ risk [23]. However, this analysis did not include other potentially confounding vascular risk factors such as BP, FG, or BMI. We observed a positive association between $A D$ risk and lipid profiles including TC, LDL-C, and TG, consistent with recent guidelines [24]. The association between increased cholesterol levels and risk of $\mathrm{AD}$ is yet to be fully understood, for the levels in the brain are independent of peripheral tissues due to the blood-brain barrier. However, considering high-fat diets are related to amyloid-beta $(A \beta)$ accumulation, the increased flux of oxysterols to the brain caused by this diet could provide an explanation for our results [25]. Increased influx of oxysterols to the brain is reported to accelerate cognitive deficits in $\mathrm{AD}$ [25].

Notably, the direction of the association between HDL$\mathrm{C}$ and $\mathrm{AD}$ risk differed from that reported in previous observational studies $[26,27]$ and guidelines. A recent metaanalysis reported no significant association between HDL$\mathrm{C}$ and AD risk [23]. The protective effects of HDL-C on $\mathrm{AD}$ risk have been observed in middle-aged adults, while studies examining patients $\geq 70$ years of age have reported no such association [28]. Furthermore, these observational studies had limited sample sizes of $<10,000$ [23]. Accumulating evidence suggests that steady-state HDL-C levels are not causally protective against cardiovascular disease $[29,30]$. Previous studies have shown that aging alters HDL-C composition, resulting in functional impairment, especially in antioxidant properties [31]. Not HDL 


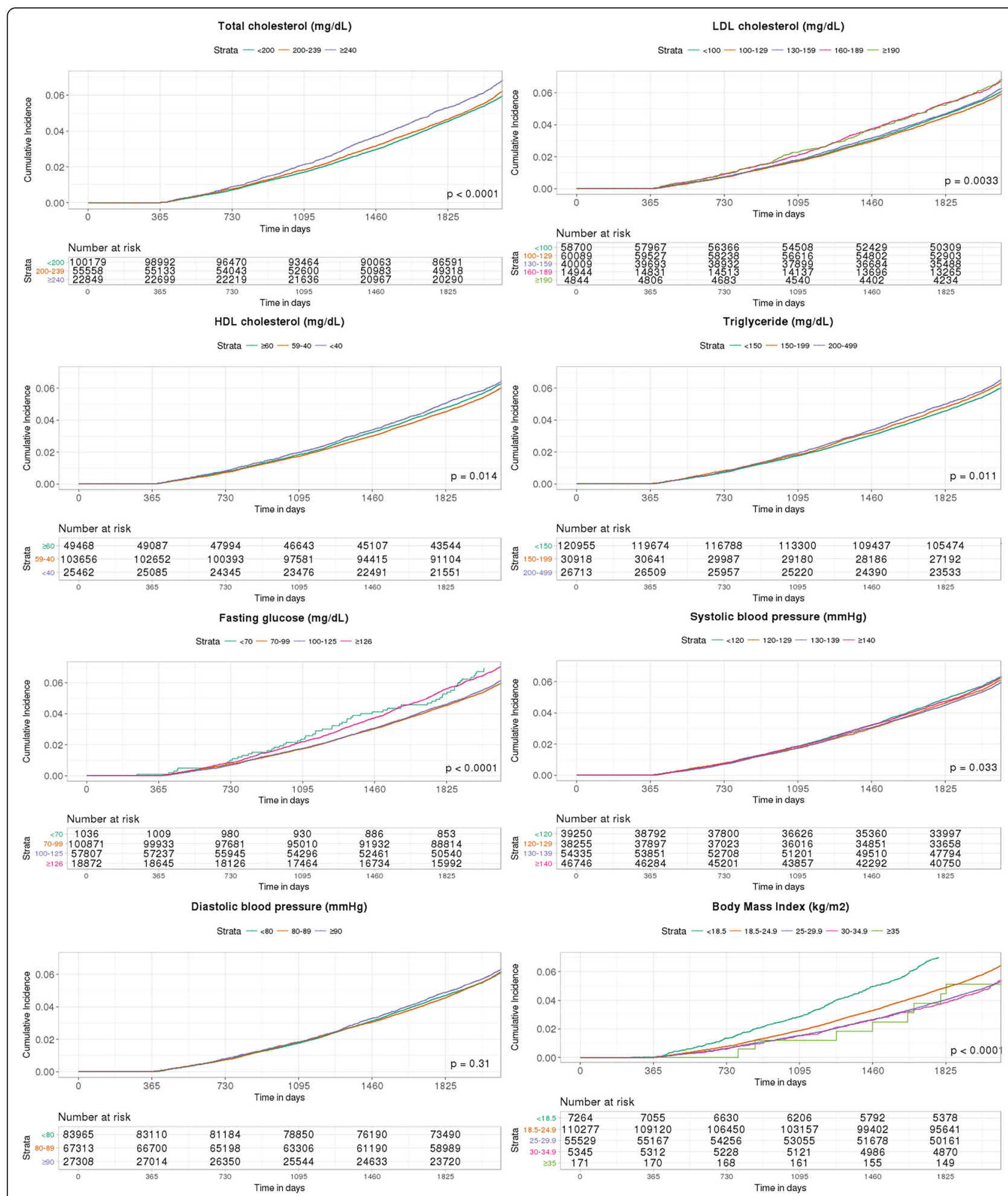

Fig. 2 The Kaplan-Meier estimates of incidence of Alzheimer's disease by vascular risk factors categorized based on the current Korean guidelines among older adults

quantity but HDL functional quality is thought to impact vascular risks by altered oxidation, inflammation, and thrombosis especially with reverse cholesterol transport
[30, 31]. These age-related changes in HDL-C could be related to the different effects of HDL-C on AD according to age group. Due to the age restrictions of the sample, we 


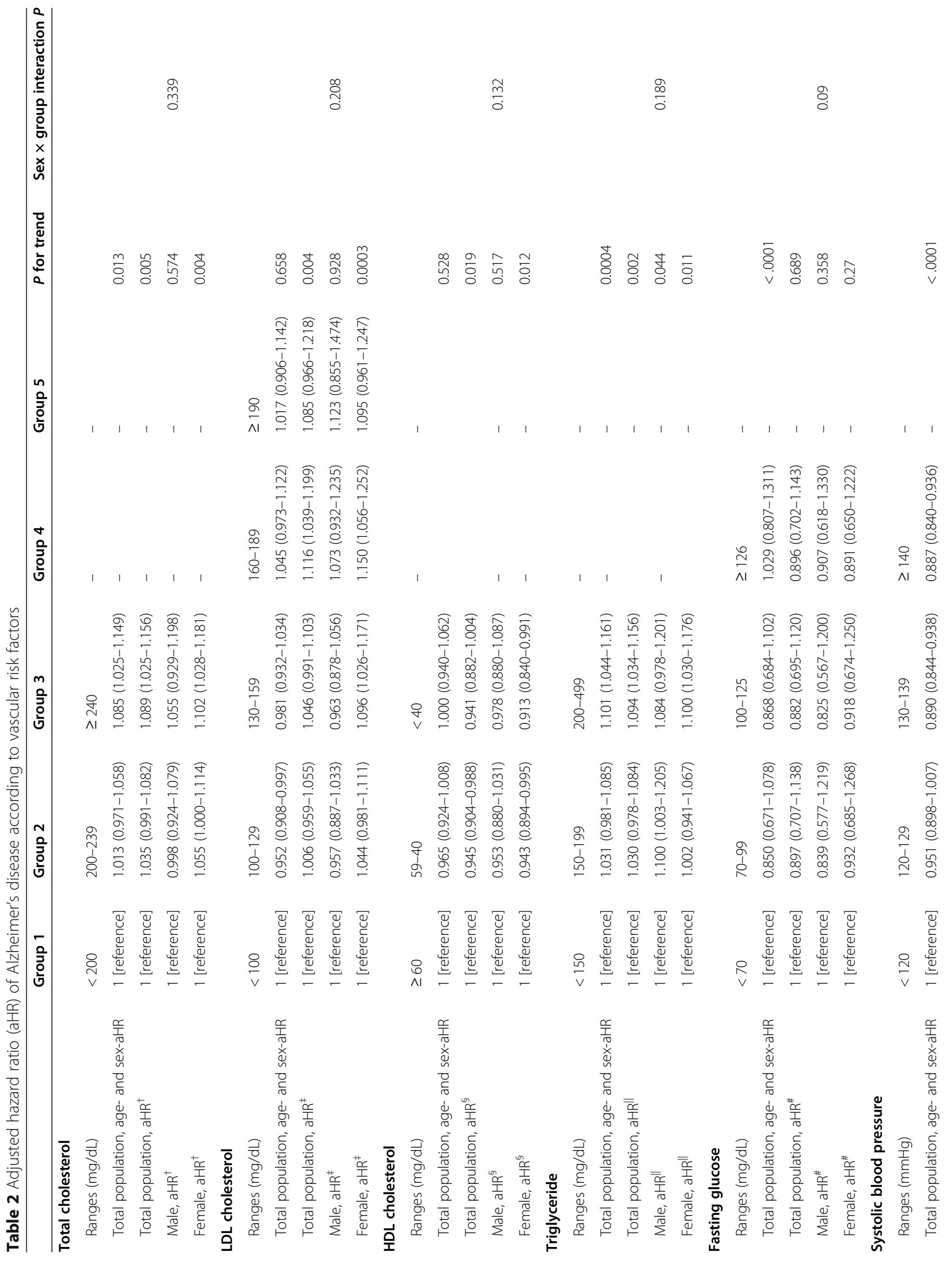




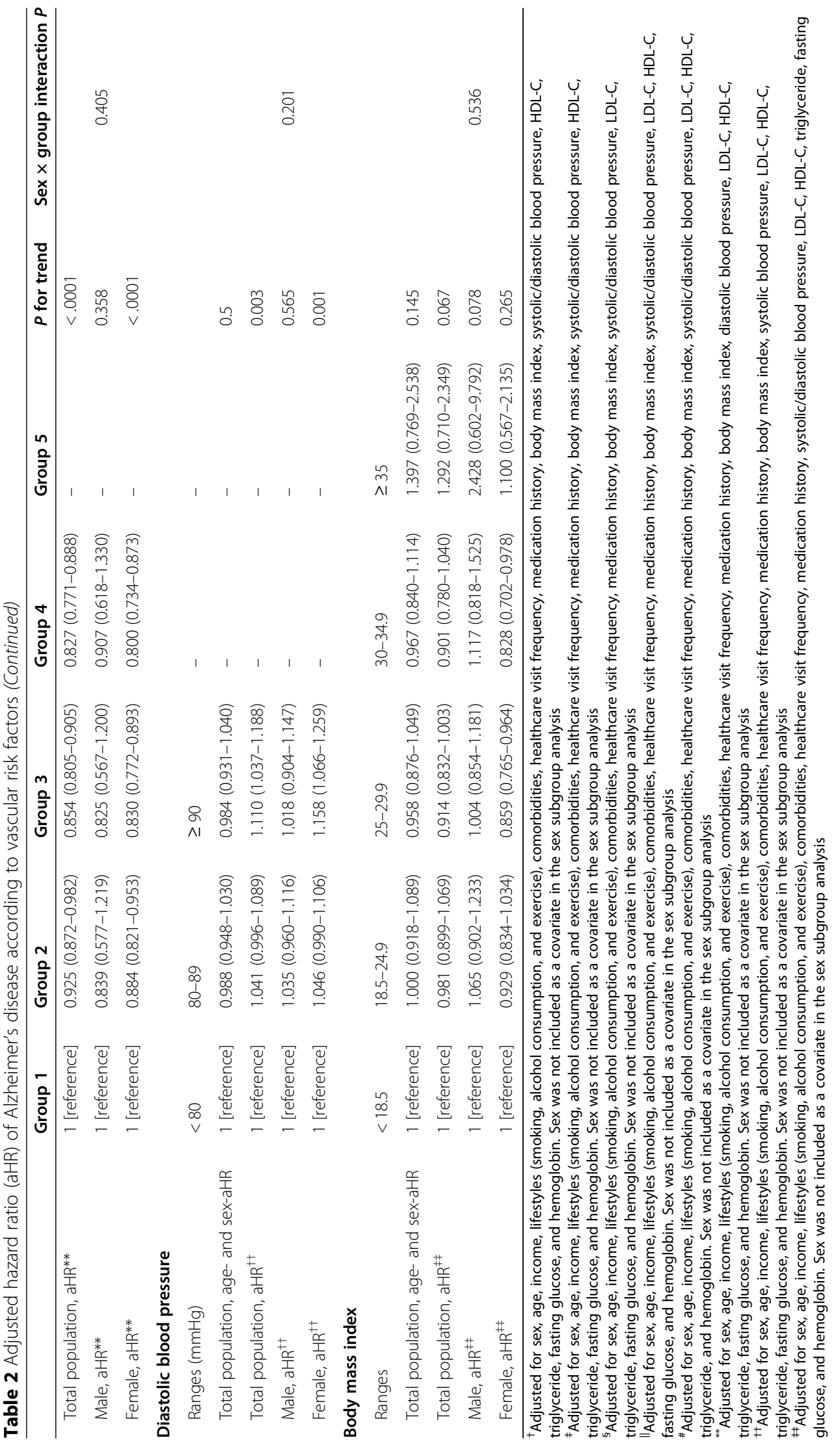




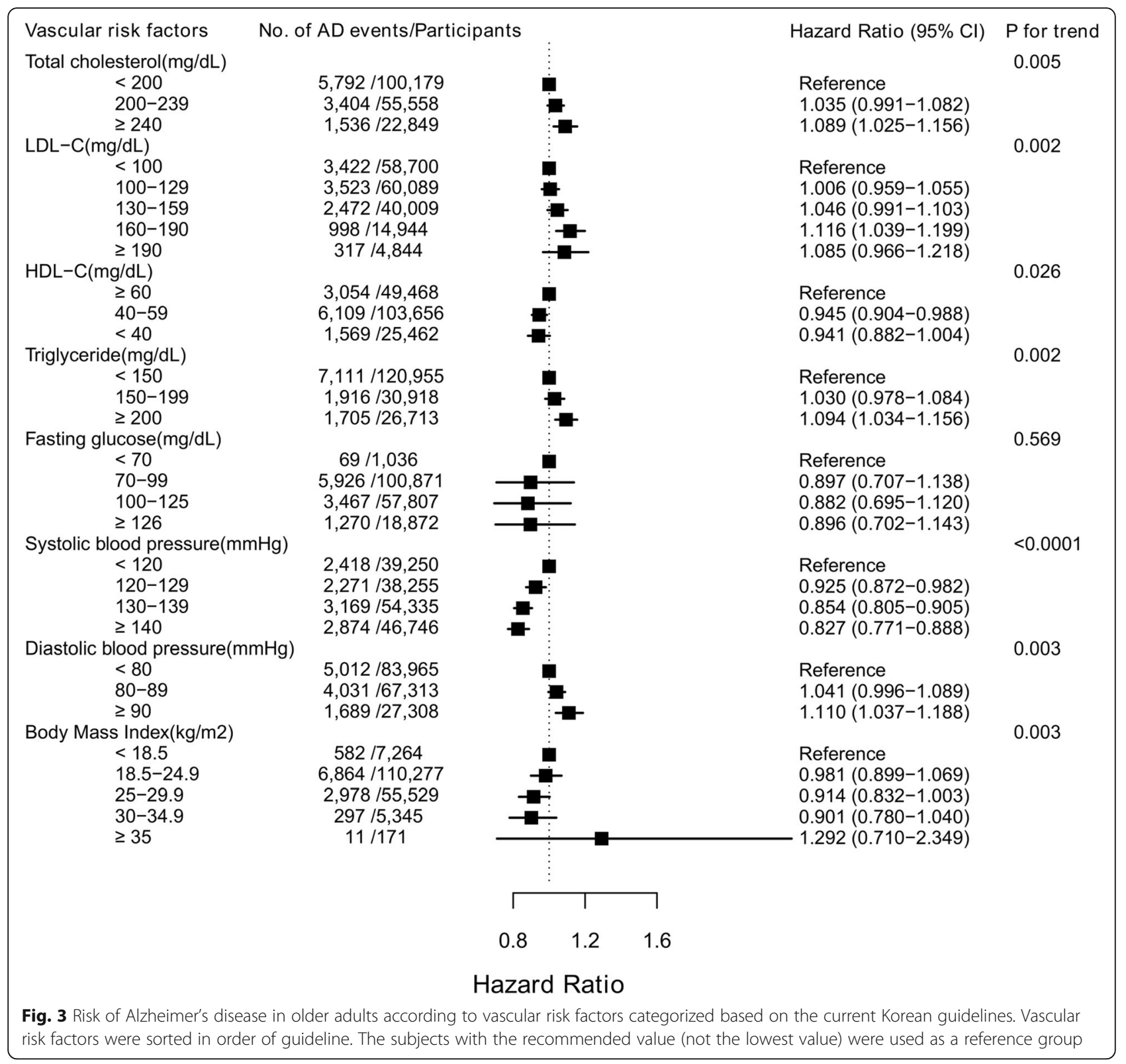

could not include a middle age comparison population. In addition, our data did not include variables for HDL quality. Further studies including HDL-C composition and function across diverse age groups are warranted.

We observed a conflicting effect of DBP and SBP on AD. We found a negative association between $\mathrm{SBP}$ and $\mathrm{AD}$, and a positive association between $\mathrm{DBP}$ and $\mathrm{AD}$. These results were also confirmed in analysis for the association between PP and AD (Fig. 4). The association between BP in older adults and cognitive impairment remains uncertain, and the results of observational studies involving older adults are inconsistent [32-34]. Several randomized controlled trials have suggested that lowering BP exerts beneficial effects on cognitive function; however, the evidence is still limited
[35-37]. Although the World Health Organization recommends antihypertensive treatment for dementia prevention [24], the American College of Physicians and the American Academy of Family Physicians [38] had previously suggested less strict SBP control for maintaining cognitive health in older adults. Our findings may indicate that this discrepancy is due to the different effects of SBP and DBP on dementia. Inverse associations of SBP with the risk of $\mathrm{AD}$ have been reported in large, population-based health studies [39] and recently supported by a Mendelian randomization study of $\mathrm{AD}$ [40]. Although SBP cannot fully represent sufficiency of cerebral blood flow, SBP is negatively associated with $\mathrm{AD}$ incidence, which could suggest sufficient cerebral oxygen levels follow insufficient 


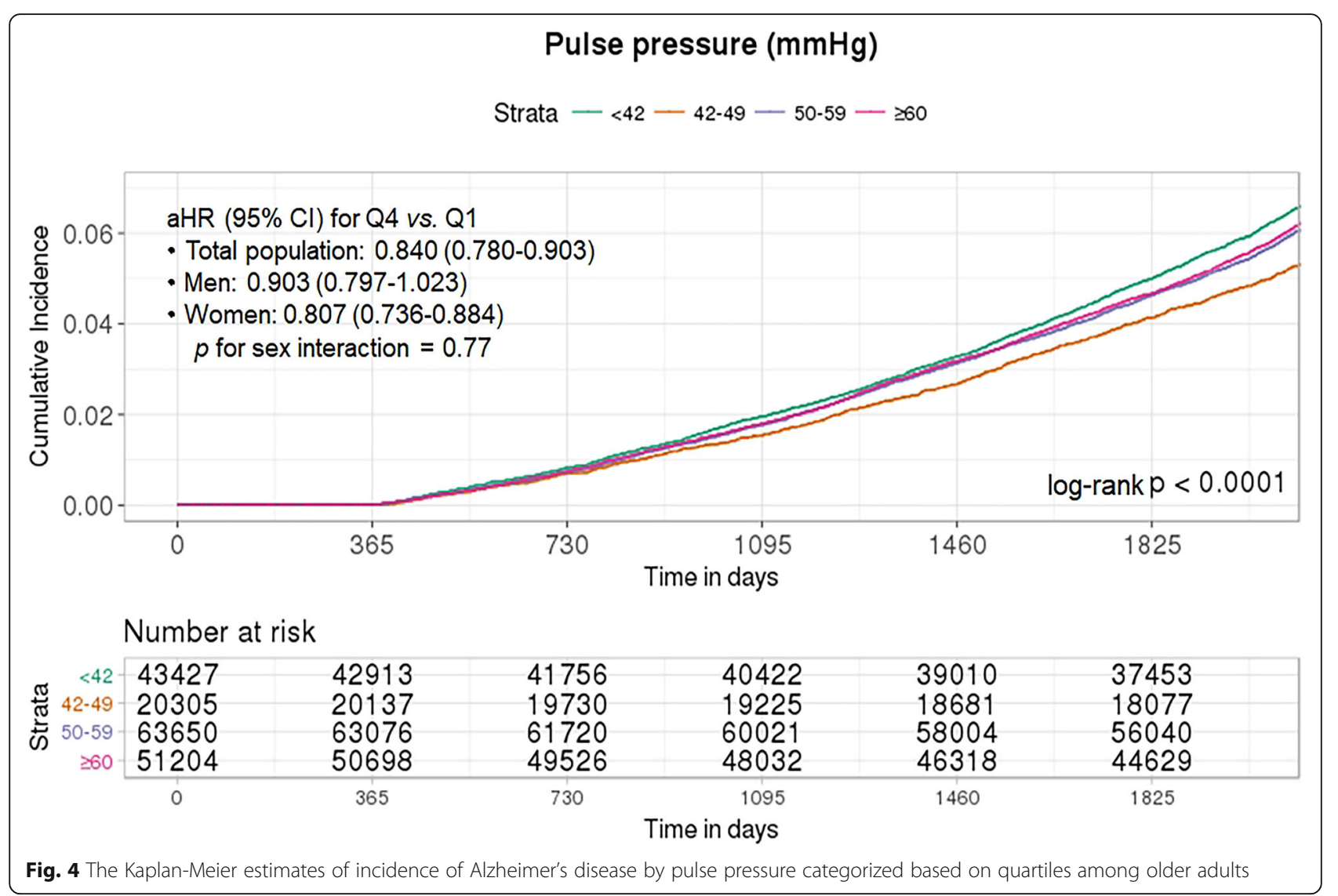

cerebral blood flow. Whether this association is derived from cerebral blood flow related to SBP or from the usage of antihypertensive medication needs further neuroimaging research in relation to cerebral blood flow. A previous report on midlife DBP could support our finding, suggesting DBP as the strongest predictor of progression of arterial stiffness, leading to AD [41]. We found a negative association between PP and AD risk, which was inconsistent with previous reports that showed that higher PP in midlife increases $A D$ risk and $A \beta$ transport dysfunction [42]. This discrepancy suggests that the effect of PP on AD risk could differ according to the age group. However, given the observational nature of our study, we could not determine whether there is a causal association between BP and dementia risk.

The association between $\mathrm{BMI}$ and $\mathrm{AD}$ risk in the present study is consistent with that reported in previous studies [16]. The protective effect of BMI may be related to the role of leptin in regulating hippocampal synaptic plasticity [43] and the additional positive effects of muscle preservation. However, these findings should be interpreted with caution to avoid a potential reverse causation effect (i.e., weight loss in preclinical AD).

Our results regarding the association between FG and $\mathrm{AD}$ risk are inconsistent with those of recent clinical trials that tested the effects of controlling serum glucose levels on reducing the risk of $\mathrm{AD}[44,45]$. However, these trials were conducted in patients with diabetes mellitus or measured restricted outcomes such as an amyloid deposition [44]. The association between FG and $\mathrm{AD}$ could differ in the general population.

In the present study, we observed differences in the association between lipid profiles and AD risk according to sex. TC and LDL-C were independent risk factors for $\mathrm{AD}$ in the female subgroup, whereas TG was a risk factor in both males and females. The incidence, risk factors, clinical symptoms, and progression of $\mathrm{AD}$ may differ between men and women [46-48]. Such sex-based differences may be due to the differences in lipid metabolism and hormone levels. For example, estrogen, which affects cholesterol removal from the liver, plays a significant role in sex-specific morbidity related to vascular risk factors [49]. These distinctive differences may also be driven by different apolipoprotein profiles in men and women. Further studies are required to determine the mechanisms underlying such sex-based differences.

The effect size for associations between vascular risk factors and $\mathrm{AD}$ risk was small in the present study (Fig. 3). Moreover, medication use did not modify this association (Additional file 1: Table S7). These findings suggest that management of vascular risk factors alone would not be enough to reduce AD risk. An integrative 
approach including management of vascular risk factors, lifestyle modifications and cognitive training could have drawn contribution to $\mathrm{AD}$ prevention in older adults [50]. However, it should be noted that the effect of controlling vascular risk factors may be stronger in early $\mathrm{AD}$ stages or mild cognitive disorders. Once the pathological change has progressed enough to require medication, prevention efforts could not reach significant effects. This could explain the small effect size of vascular risk factors on $\mathrm{AD}$ and the little significance of medication modification in our results.

Our large-scale study is advantageous in that we utilized nationwide real-world data representing older adults in the Korean population. Moreover, we addressed multiple vascular risk factors and stratified analyses according to sex and age groups. As most other studies have focused on midlife vascular risk factors related to the risk of dementia, our findings may provide further explanations, representing a clear association with those related to the risk in older adults. This study also had several limitations. First, although we comprehensively adjusted for various confounders including socioeconomic or lifestyle factors, we did not consider potential confounders such as education, occupational attainment, exercise, diet, sufficient sleep, family history, and genetics (apolipoprotein E genotype). The lack of information on the level of hemoglobin A1c, a standard tool to determine average blood glucose control levels, could be a significant limitation, which needs to be elaborated through future research representing actual glucose control. Second, the operational definition of $\mathrm{AD}$ may be associated with misdiagnosis or underdiagnosis. However, the rate of $\mathrm{AD}$ in our study population was similar to rates reported in epidemiological studies conducted in South Korea [51]. Additionally, we included prescription information in the operational criteria to improve the accuracy of diagnosis. In South Korea, clinicians are required to document clinical diagnoses of dementia as well as the results of neuropsychological tests in order to prescribe the medications outlined in our inclusion criteria. Dementia ascertainment, defined as prescribing cognitive enhancer, could have limited information to fully represent the actual onset of $\mathrm{AD}$, considering the insidious progress of $\mathrm{AD}$ in the clinical situation. Lack of information regarding biomarkers and $\mathrm{AD}$ confirmation via imaging might have led to the limitation of a heterogeneous group with numerous contributing pathological substrates. The lack of information related to the severity stage of $\mathrm{AD}$ also had limitation to observe association between the role of vascular risk factors and the course of AD. Third, because the study population included individuals from a single country, our findings may not be generalizable to people from other countries. Fourth, given the observational nature of our study, we could not determine causal relationships between vascular risk factors and AD risk. And careful interpretation should be conducted with respect to reverse causation effect, for changes in vascular metrics occur proximal to the onset of major neurocognitive dysfunction rather than early stages of AD pathophysiology. Last, since our study population was based on the National Health Insurance Service-Senior Cohort ( $\geq 60$ years), we could not investigate whether midlife and later life vascular risk factors have different effects on incident AD. Future studies examining the differences among midlife and later life vascular risk factors from a same population would be informative.

\section{Conclusions}

In the present study, we observed a positive association between $\mathrm{AD}$ risk and TC, LDL-C, HDL-C, TG, and DBP among older adults. Further, SBP, BMI, and PP exhibited robust negative associations with $\mathrm{AD}$ risk. Associations between AD and TC, LDL-C, HDL-C, and DBP differed according to sex. More elaborate, prospective studies are required to gain a greater understanding of the association between vascular risk factors and $\mathrm{AD}$ in older adults.

\section{Supplementary information}

Supplementary information accompanies this paper at https://doi.org/10. 1186/s13195-020-00690-7.

\begin{abstract}
Additional file 1: Table S1. The current Korean guidelines for vascular risk factors. Table S2. Detailed results for risk of Alzheimer's disease according to vascular risk factors. Table S3. Adjusted hazard ratios of risk factors associated with incident Alzheimer's disease by Cox proportional hazards model $(n=178,586)$. Table S4. Risk of Alzheimer's disease in older adults according to pulse pressure categorized based on quartiles. Table S5. Risk of Alzheimer's disease according to vascular risk factors in male subgroup ( $n=81,242)$. Table S6. Risk of Alzheimer's disease according to vascular risk factors in female subgroup $(n=97,344)$. Table S7. Stratified analysis according to medications prescription during the first 3 years of follow-up.
\end{abstract}

\section{Abbreviations}

AD: Alzheimer's disease; aHR: Adjusted hazard ratio; Aß: Amyloid-beta; BP: Blood pressure; BMI: Body mass index; DALY: Disability-adjusted life year; DBP: Diastolic blood pressure; FG: Fasting glucose; HDL-C: High-density lipoprotein cholesterol; ICD-10: International Classification of Diseases, Tenth Revision; LDL-C: Low-density lipoprotein cholesterol; NHID: National Health Insurance Database; NHIS-SC: National Health Insurance Service-Senior Cohort; PH: Proportional hazard; PP: Pulse pressure; SBP: Systolic blood pressure; TC: Total cholesterol; TG: Triglycerides; VIF: Variance inflation factor

\section{Acknowledgements}

Not applicable.

\section{Authors' contributions}

HL conceived and designed the study, acquired and analyzed the data, interpreted the study findings, and drafted the manuscript. KK conceived and designed the study; defined the exclusion criteria and exposure, outcome, and covariate categories; interpreted the study findings; and drafted the manuscript. YCL, SK, HHW, TYY, EML, JMK, ML, and DKK designed the study; defined the exclusion criteria and exposure, outcome, and covariate categories; interpreted the study findings; and drafted the manuscript. WM conceived and designed the study, interpreted the study findings, supervised and directed the conduct of the study, and critically 
reviewed the manuscript. The corresponding author attests that all listed authors meet authorship criteria and that no others meeting the criteria have been omitted. WM is the guarantor of the work. HL and KK contributed equally to this work as co-first authors. All authors read and approved the final manuscript.

\section{Funding}

This work was supported by the National Research Foundation of Korea (NRF) Grant funded by the Ministry of Science and ICT (Information and Communication Technologies), South Korea [grant number NRF2018R1C1B6001708; W Myung], and by the Soonchunhyang University Research Fund [H Lee]. The funding source was not involved in the design and conduct of the study; collection, management, analysis, and interpretation of the data; preparation, review, or approval of the manuscript; and decision to submit the manuscript for publication.

\section{Availability of data and materials}

This study is based on National Health Insurance Service (NHIS) registry data in South Korea (NHIS-2018-2-198). Because these data belong to the NHIS, the authors are not permitted to share them, except in aggregate (as, for example, in a publication). However, interested parties can obtain the data on which the study was based by submitting a research protocol to the NHIS (https://nhiss.nhis.or.kr/bd/ab/bdaba000eng.do). The analytic/statistical codes are available from the corresponding author (wjmyung@snubh.org, WM), upon reasonable request.

\section{Ethics approval and consent to participate}

The study was approved by the Institutional Review Board of Seoul National University Bundang Hospital, which waived the requirement for informed consent due to the nature of the study. All data were anonymized to maintain confidentiality.

\section{Consent for publication}

\section{Not applicable.}

\section{Competing interests}

The authors declare that they have no competing interests.

\section{Author details}

${ }^{1}$ Department of Health Administration and Management, College of Medical Sciences, Soonchunhyang University, Asan, South Korea. ${ }^{2}$ Department of Psychiatry, Veteran Health Service Medical Center, Seoul, South Korea. ${ }^{3}$ Samsung Advanced Institute for Health Sciences and Technology (SAIHST), Sungkyunkwan University, Samsung Medical Center, Seoul, South Korea. ${ }^{4}$ Division of Endocrinology and Metabolism, Department of Medicine, Wonkwang Medical Center, Wonkwang University School of Medicine, Iksan, South Korea. ${ }^{5}$ Department of Health Science, Dongduk Women's University, Seoul, South Korea. 'Department of Psychiatry, Gil Medical Center, Gachon University College of Medicine, Incheon, South Korea. ${ }^{7}$ The Department of General Practice, Melbourne Medical School, The University of Melbourne, Melbourne, Australia. ${ }^{8}$ Department of Psychiatry, Samsung Medical Center, Sungkyunkwan University School of Medicine, Seoul, South Korea. ${ }^{9}$ Department of Neuropsychiatry, Seoul National University Bundang Hospital, Seongnam-si, South Korea.

\section{Received: 12 April 2020 Accepted: 15 September 2020}

Published online: 26 September 2020

\section{References}

1. Group GBDNDC. Global, regional, and national burden of neurological disorders during 1990-2015: a systematic analysis for the Global Burden of Disease Study 2015. Lancet Neurol. 2017;16(11):877-97.

2. Alzheimer's A. 2015 Alzheimer's disease facts and figures. Alzheimers Dement. 2015;11(3):332-84

3. Kivipelto M, Mangialasche F. Alzheimer disease: to what extent can Alzheimer disease be prevented? Nat Rev Neurol. 2014;10(10):552-3.

4. Xu W, Tan L, Wang HF, Jiang T, Tan MS, Tan L, Zhao QF, Li JQ, Wang J, Yu JT. Meta-analysis of modifiable risk factors for Alzheimer's disease. J Neurol Neurosurg Psychiatry. 2015;86(12):1299-306.
5. Reiman EM, Langbaum JB, Tariot PN, Lopera F, Bateman RJ, Morris JC, Sperling RA, Aisen PS, Roses AD, Welsh-Bohmer KA, et al. CAP--advancing the evaluation of preclinical Alzheimer disease treatments. Nat Rev Neurol. 2016;12(1):56-61.

6. Sinclair AJ, Hillson R, Bayer AJ, National Expert Working G. Diabetes and dementia in older people: a best clinical practice statement by a multidisciplinary National Expert Working Group. Diabet Med. 2014;31(9):1024-31.

7. Gandy S, DeKosky ST. Toward the treatment and prevention of Alzheimer's disease: rational strategies and recent progress. Annu Rev Med. 2013;64:367-83.

8. Gottesman RF, Schneider AL, Zhou Y, Coresh J, Green E, Gupta N, Knopman DS, Mintz A, Rahmim A, Sharrett AR, et al. Association between midlife vascular risk factors and estimated brain amyloid deposition. JAMA. 2017; 317(14):1443-50.

9. McGrath ER, Beiser AS, DeCarli C, Plourde KL, Vasan RS, Greenberg SM, Seshadri S. Blood pressure from mid- to late life and risk of incident dementia. Neurology. 2017;89(24):2447-54.

10. Wang KC, Woung LC, Tsai MT, Liu CC, Su YH, Li CY. Risk of Alzheimer's disease in relation to diabetes: a population-based cohort study. Neuroepidemiology. 2012;38(4):237-44.

11. Akomolafe A, Beiser A, Meigs JB, Au R, Green RC, Farrer LA, Wolf PA, Seshadri S. Diabetes mellitus and risk of developing Alzheimer disease: results from the Framingham Study. Arch Neurol. 2006;63(11):1551-5.

12. Solomon A, Kareholt I, Ngandu T, Winblad B, Nissinen A, Tuomilehto J, Soininen H, Kivipelto M. Serum cholesterol changes after midlife and late-life cognition: twenty-one-year follow-up study. Neurology. 2007;68(10):751-6.

13. Arvanitakis Z, Schneider JA, Wilson RS, Bienias JL, Kelly JF, Evans DA, Bennett DA. Statins, incident Alzheimer disease, change in cognitive function, and neuropathology. Neurology. 2008;70(19 Pt 2):1795-802.

14. Haag MD, Hofman A, Koudstaal PJ, Stricker BH, Breteler MM. Statins are associated with a reduced risk of Alzheimer disease regardless of lipophilicity. The Rotterdam Study. J Neurol Neurosurg Psychiatry. 2009;80(1):13-7.

15. Pappolla MA, Bryant-Thomas TK, Herbert D, Pacheco J, Fabra Garcia M, Manjon M, Girones X, Henry TL, Matsubara E, Zambon D, et al. Mild hypercholesterolemia is an early risk factor for the development of Alzheimer amyloid pathology. Neurology. 2003;61(2):199-205.

16. Pegueroles J, Jimenez A, Vilaplana E, Montal V, Carmona-Iragui M, Pane A, Alcolea D, Videla L, Casajoana A, Clarimon J, et al. Obesity and Alzheimer's disease, does the obesity paradox really exist? A magnetic resonance imaging study. Oncotarget. 2018;9(78):34691-8.

17. Daviglus ML, Plassman BL, Pirzada A, Bell CC, Bowen PE, Burke JR, Connolly ES Jr, Dunbar-Jacob JM, Granieri EC, McGarry K, et al. Risk factors and preventive interventions for Alzheimer disease: state of the science. Arch Neurol. 2011;68(9):1185-90.

18. Volgman AS, Bairey Merz CN, Aggarwal NT, Bittner V, Bunch TJ, Gorelick PB, Maki P, Patel HN, Poppas A, Ruskin J, et al. Sex differences in cardiovascular disease and cognitive impairment: another health disparity for women? J Am Heart Assoc. 2019;8(19):e013154.

19. Lee J, Lee JS, Park S-H, Shin SA, Kim K: Cohort Profile: The National Health Insurance Service-National Sample Cohort (NHIS-NSC), South Korea. Int J Epidemiol 2016:dyv319.

20. Committee for the Korean Guidelines for the Management of D. 2015 Korean guidelines for the management of dyslipidemia: executive summary (English translation). Korean Circ J. 2016;46(3):275-306.

21. Asmar R, Darne B, el Assaad M, Topouchian J. Assessment of outcomes other than systolic and diastolic blood pressure: pulse pressure, arterial stiffness and heart rate. Blood Press Monit. 2001;6(6):329-33.

22. Kim CT, Myung W, Lewis M, Lee H, Kim SE, Lee K, Lee C, Choi J, Kim H, Carroll BJ: Exposure to general anesthesia and risk of dementia: a nationwide population-based cohort study. J Alzheimer's Dis 2018(Preprint):1-11.

23. Anstey KJ, Ashby-Mitchell K, Peters R. Updating the evidence on the association between serum cholesterol and risk of late-life dementia: review and meta-analysis. J Alzheimers Dis. 2017;56(1):215-28.

24. WHO. In: Risk reduction of cognitive decline and dementia: WHO guidelines. edn. Geneva; 2019.

25. Mateos L, Akterin S, Gil-Bea FJ, Spulber S, Rahman A, Bjorkhem I, Schultzberg M, Flores-Morales A, Cedazo-Minguez A. Activity-regulated cytoskeletonassociated protein in rodent brain is down-regulated by high fat diet in vivo and by 27-hydroxycholesterol in vitro. Brain Pathol. 2009;19(1):69-80.

26. Reitz C, Tang MX, Luchsinger J, Mayeux R. Relation of plasma lipids to Alzheimer disease and vascular dementia. Arch Neurol. 2004;61(5):705-14.

27. Tynkkynen J, Hernesniemi JA, Laatikainen T, Havulinna AS, Sundvall J, Leiviska J, Salo P, Salomaa V. Apolipoproteins and HDL cholesterol do not 
associate with the risk of future dementia and Alzheimer's disease: the National Finnish population study (FINRISK). Age (Dordr). 2016;38(5-6): 465-73.

28. Button EB, Robert J, Caffrey $T M$, Fan J, Zhao W, Wellington CL. HDL from an Alzheimer's disease perspective. Curr Opin Lipidol. 2019;30(3):224-34.

29. Zanoni P, Khetarpal SA, Larach DB, Hancock-Cerutti WF, Millar JS, Cuchel M, DerOhannessian S, Kontush A, Surendran P, Saleheen D, et al. Rare variant in scavenger receptor BI raises HDL cholesterol and increases risk of coronary heart disease. Science (New York, NY). 2016;351(6278):1166-71.

30. Zhong WW, Van Horn L, Cornelis MC, Wilkins JT, Ning H, Carnethon MR, Greenland P, Mentz RJ, Tucker KL, Zhao L, et al. Associations of dietary cholesterol or egg consumption with incident cardiovascular disease and mortality. Jama. 2019;321(11):1081-95.

31. Holzer M, Trieb M, Konya V, Wadsack C, Heinemann A, Marsche G. Aging affects high-density lipoprotein composition and function. Biochim Biophys Acta. 2013;1831(9):1442-8.

32. Rouch L, Cestac P, Hanon O, Cool C, Helmer C, Bouhanick B, Chamontin B, Dartigues JF, Vellas B, Andrieu S. Antihypertensive drugs, prevention of cognitive decline and dementia: a systematic review of observational studies, randomized controlled trials and meta-analyses, with discussion of potential mechanisms. CNS Drugs. 2015:29(2):113-30.

33. Nilsson SE, Read S, Berg S, Johansson B, Melander A, Lindblad U. Low systolic blood pressure is associated with impaired cognitive function in the oldest old: longitudinal observations in a population-based sample 80 years and older. Aging Clin Exp Res. 2007;19(1):41-7.

34. Mossello E, Pieraccioli M, Nesti N, Bulgaresi M, Lorenzi C, Caleri V, Tonon E, Cavallini MC, Baroncini C, Di Bari M, et al. Effects of low blood pressure in cognitively impaired elderly patients treated with antihypertensive drugs. JAMA Intern Med. 2015;175(4):578-85.

35. Peters R, Beckett N, Forette F, Tuomilehto J, Clarke R, Ritchie C, Waldman A, Walton I, Poulter R, Ma S, et al. Incident dementia and blood pressure lowering in the Hypertension in the Very Elderly Trial cognitive function assessment (HYVET-COG): a double-blind, placebo controlled trial. Lancet Neurol. 2008;7(8):683-9.

36. Williamson JD, Launer LJ, Bryan RN, Coker LH, Lazar RM, Gerstein HC, Murray AM, Sullivan MD, Horowitz KR, Ding J, et al. Cognitive function and brain structure in persons with type 2 diabetes mellitus after intensive lowering of blood pressure and lipid levels: a randomized clinical trial. JAMA Intern Med. 2014;174(3):324-33.

37. Group SMIftSR, Williamson JD, Pajewski NM, Auchus AP, Bryan RN, Chelune G, Cheung AK, Cleveland ML, Coker LH, Crowe MG et al: Effect of intensive vs standard blood pressure control on probable dementia: a randomized clinical trial. JAMA 2019, 321(6):553-561.

38. Qaseem A, Wilt TJ, Rich R, Humphrey LL, Frost J, Forciea MA, Clinical Guidelines Committee of the American College of $\mathrm{P}$, the Commission on Health of the P, Science of the American Academy of Family P: Pharmacologic treatment of hypertension in adults aged 60 years or older to higher versus lower blood pressure targets: a clinical practice guideline from the American College of Physicians and the American Academy of Family Physicians. Ann Intern Med 2017, 166(6):430-437.

39. Gabin JM, Tambs K, Saltvedt I, Sund E, Holmen J. Association between blood pressure and Alzheimer disease measured up to 27 years prior to diagnosis: the HUNT Study. Alzheimers Res Ther. 2017;9(1):37.

40. Ostergaard SD, Mukherjee S, Sharp SJ, Proitsi P, Lotta LA, Day F, Perry JR, Boehme KL, Walter S, Kauwe JS, et al. Associations between potentially modifiable risk factors and Alzheimer disease: a Mendelian randomization study. PLoS Med. 2015;12(6):e1001841 discussion e1001841.

41. Webb AJS. Progression of arterial stiffness is associated with midlife diastolic blood pressure and transition to late-life hypertensive phenotypes. J Am Heart Assoc. 2020;9(1):e014547.

42. Jiang Y, Shang S, Li P, Chen C, Dang L, Wang J, Huo K, Deng M, Wang J, Qu Q. Pulse pressure is associated with plasma amyloid-beta transport dysfunction. J Hypertens. 2018;36(3):569-79.

43. Oomura Y, Hori N, Shiraishi T, Fukunaga K, Takeda H, Tsuji M, Matsumiya T, Ishibashi M, Aou S, Li XL, et al. Leptin facilitates learning and memory performance and enhances hippocampal CA1 long-term potentiation and CaMK II phosphorylation in rats. Peptides. 2006;27(11):2738-49.

44. Li TC, Yang CP, Tseng ST, Li Cl, Liu CS, Lin WY, Hwang KL, Yang SY, Chiang $\mathrm{JH}$, Lin CC. Visit-to-visit variations in fasting plasma glucose and HbA1C associated with an increased risk of Alzheimer disease: Taiwan diabetes study. Diabetes Care. 2017;40(9):1210-7.
45. Watson KT, Wroolie TE, Tong G, Foland-Ross LC, Frangou S, Singh M, Mclntyre RS, Roat-Shumway S, Myoraku A, Reiss AL, et al. Neural correlates of liraglutide effects in persons at risk for Alzheimer's disease. Behav Brain Res. 2019;356:271-8.

46. Pike CJ. Sex and the development of Alzheimer's disease. J Neurosci Res. 2017;95(1-2):671-80.

47. Neu SC, Pa J, Kukull W, Beekly D, Kuzma A, Gangadharan P, Wang LS, Romero $\mathrm{K}$, Arneric SP, Redolfi A, et al. Apolipoprotein E genotype and sex risk factors for Alzheimer disease: a meta-analysis. JAMA Neurol. 2017;74(10):1178-89.

48. Riedel BC, Thompson PM, Brinton RD. Age, APOE and sex: triad of risk of Alzheimer's disease. J Steroid Biochem Mol Biol. 2016;160:134-47.

49. Della Torre S, Mitro N, Fontana R, Gomaraschi M, Favari E, Recordati C, Lolli F, Quagliarini F, Meda C, Ohlsson C, et al. An essential role for liver ERalpha in coupling hepatic metabolism to the reproductive cycle. Cell Rep. 2016;15(2):360-71.

50. Coley N, Ngandu T, Lehtisalo J, Soininen H, Vellas B, Richard E, Kivipelto M, Andrieu $\mathrm{S}$, Hatice $\mathrm{F}$, groups MD: Adherence to multidomain interventions for dementia prevention: data from the FINGER and MAPT trials. Alzheimers Dement. 2019;15(6): 729-41.

51. Kim YJ, Han JW, So YS, Seo JY, Kim KY, Kim KW. Prevalence and trends of dementia in Korea: a systematic review and meta-analysis. J Korean Med Sci. 2014;29(7):903-12.

\section{Publisher's Note}

Springer Nature remains neutral with regard to jurisdictional claims in published maps and institutional affiliations.
Ready to submit your research? Choose BMC and benefit from:

- fast, convenient online submission

- thorough peer review by experienced researchers in your field

- rapid publication on acceptance

- support for research data, including large and complex data types

- gold Open Access which fosters wider collaboration and increased citations

- maximum visibility for your research: over $100 \mathrm{M}$ website views per year

At BMC, research is always in progress.

Learn more biomedcentral.com/submissions 